University of Wollongong

Research Online

Faculty of Social Sciences - Papers (Archive) Faculty of Arts, Social Sciences \& Humanities

2014

Advocacy by parents of young children with special needs: Activities, processes, and perceived effectiveness

Amy Conley Wright

University of Wollongong, acwright@uow.edu.au

Sarah Taylor

California State University

Follow this and additional works at: https://ro.uow.edu.au/sspapers

Part of the Education Commons, and the Social and Behavioral Sciences Commons

Research Online is the open access institutional repository for the University of Wollongong. For further information contact the UOW Library: research-pubs@uow.edu.au 


\title{
Advocacy by parents of young children with special needs: Activities, processes, and perceived effectiveness
}

\author{
Abstract \\ This article examines parental advocacy for young children with disabilities using a subset of data drawn \\ from a larger exploratory and descriptive study on parental advocacy for children with disabilities from \\ birth to age 18 with a sample of 400 participants. Because this article focuses on parents of children \\ from birth to age 6 , only parents $(n=76)$ meeting this criterion were selected. Data were collected through \\ an online survey, with a snowball sample generated through e-mail lists and social media groups. The \\ survey included questions on demographics, types of advocacy settings, perceived effectiveness of \\ advocacy efforts, and an example of a successful advocacy effort. Parental advocacy was most common \\ in schools, medical clinics, social services, and social media and involved processes such as educating \\ oneself about the child's condition and rights for services, educating others including professionals, and \\ making persistent efforts. These findings suggest advocacy on behalf of children with disabilities starts \\ early and is important from birth to age 6. Policy and social work practice should help parents with \\ support, knowledge, and skills to be effective advocates for their children. Future research is \\ recommended to explore the relationships between advocacy, empowerment, coping, and resilience in \\ parents of children with special needs.
}

\section{Keywords}

young, activities, parents, processes, advocacy, perceived, effectiveness, needs, special, children

\section{Disciplines}

Education | Social and Behavioral Sciences

\section{Publication Details}

Conley Wright, A. \& Taylor, S. (2014). Advocacy by parents of young children with special needs: Activities, processes, and perceived effectiveness. Journal of Social Service Research, 40 (5), 591-605. 
Advocacy by Parents of Young Children with Special Needs:

Activities, Processes, and Perceived Effectiveness

Amy Conley Wright, MSW, PhD*

Senior Lecturer in Social Work, School of Health \& Society

University of Wollongong

Sarah Taylor, MSW, PhD

Assistant Professor, Department of Social Work,

California State University, East Bay

*Corresponding author 


\begin{abstract}
This article examines parental advocacy for young children with disabilities. Drawn from a larger exploratory and descriptive study on parental advocacy for children with disabilities birth to 18 , with a total sample of $n=400$, this article reports on a subset of responses $(n=76)$ from parents of children birth to age 6 only. Original data was collected through an online survey, with a snowball sample generated through email lists and social media groups. Survey questions included questions on demographics, types of settings for advocacy, perceived effectiveness of advocacy efforts, and an example of a successful advocacy effort. Parental advocacy was most common in schools, medical clinics, social services, and social media. The primary processes found to be associated with parental advocacy are educating oneself about the child's condition and rights for accommodations and services; educating others, including professionals and the general public; and making persistent efforts. These findings suggest advocacy on behalf of children with disabilities begins early in life, and that policy and social work practice should help parents with support, knowledge, and skills to be effective advocates for their children. Future research should explore the relationships between advocacy, empowerment, coping, and resilience in parents of children with special needs.
\end{abstract}


A wealth of research has documented the challenges of raising a child with special needs, including relationship stress, financial difficulties, and mental and physical health problems (Olsson \& Hwang, 2001; Rayner \& Moore, 2007). Though this research has made an important contribution to understanding the problems associated with parenting a child with special needs, it has been critiqued as being overly focused on deficits, rather than strengths (Gupta \& Singhal, 2004). This paper builds on an emerging literature that seeks to address this lacuna by exploring strengths, hope, coping and resilience in parents of children with special needs (Levine, 2009; Rivera, 2009). One branch of this literature suggests that advocacy, on behalf of one’s child and to improve services for all children, may create a sense of empowerment while resulting in better service provision (Hess, Molina \& Kozleski, 2006). This study focuses on the experiences of parents $(n=76)$ of children ages birth to six, drawn from a larger sample of parents of children ages birth to eighteen ( $n=400)$, who responded to an online survey regarding their efforts to advocate for their special needs child.

\section{Introduction and Literature Review}

Early childhood is a time of critical development, forming the foundation for later life and influencing health, social, and academic outcomes. For children with disabilities, this period of childhood provides a particularly important opportunity for early intervention (Berlin, BrooksGunn, McCarton \& McCormick, 1998). Yet disabilities are under detected in early childhood, with research suggesting that the majority of children may be undiagnosed until reaching school age (Sices, 2007). Furthermore, children with diagnosed delays are under served by early intervention programs (Rosenberg, Zhang \& Robinson, 2008). Advocacy by parents during early childhood is crucial for encouraging appropriate diagnosis and treatment. Parental concerns have been demonstrated to be predictive of developmental problems (Tervo, 2005) and 
as accurate as quality screening tests in terms of identifying potential delays and disabilities (Glascoe, 1999), with parents typically expressing concerns months or even years before receiving a formal diagnosis (Bailey, Skinner, Hatton \& Roberts, 2000; Lock, Shapiro, Ross \& Capute, 1986; Shevell, Majnemer, Rosenbaum \& Abrahamowicz, 2001). Parental advocacy is necessary for ensuring that children receive the services they need to maximize their developmental potential.

Advocacy by families of children with special needs has been defined as “A non-violent empowerment and support process, through which families with disabled relatives can constructively express dissatisfaction and contribute to creative solutions to problems existing in human services systems” (Munro, 1991, cited in Nachshen \& Jamieson, 2000, p. 39). Case advocacy may involve representing a child’s interests through phone calls, office meetings, and letters (Balcazar, Keys, Bertram \& Rizzo, 1996; Wang, Mannan, Poston, Turnbull, \& Summers, 2004) as well as presenting reasons for educational or other accommodations and monitoring progress (Duquette, Stodel, Fullarton \& Hagglund, 2011). Some parents may shift from case to cause advocacy, as they expand their focus to other individuals with disabilities by organizing with other parents (Mlawer, 1993).

Parents have been called the natural advocates for their children, due to their commitments and investments in their child's well-being (McCammon, Spencer, \& Friesen, 2001). The need to advocate for children with special needs is more pronounced than for typically developing children (Mlawer, 1993). This advocacy expectation may be explicit, as with early intervention programs that prepare parents to be advocates for their children (Wang et al, 2004), or implicit in the design of policies that require parents to initiate the process of securing services for their children (Kalyanpur, 2000). Beneath this advocacy expectation is the 
assumption that parents have the time, interest, and inclination to assume this advocacy role, as well as the knowledge and skills to function within this role (Turnbull \& Leonard, 1981). Others have argued against the advocacy expectation and have instead identified advocacy for children with special needs as the responsibility of professionals who have undertaken the responsibilities and developed the skills and knowledge to fulfill this role (Mlawer, 1993).

Whether or not parents elect to become advocates for their children may be related to their level of empowerment. Content analyses of definitions of empowerment identify the key concepts as self-efficacy, participation and collaboration, sense of control, meeting personal needs, understanding the environment, access to resources, and personal action (Dempsey \& Foreman, 1997; Dunst, Trivette \& LaPointe, 1992). The process of empowerment involves assessing personal power and taking control over one’s life. Related outcomes can include improved abilities related to autonomy, decision-making, communication, and advocacy skills (Carr, 2011). It has been proposed that parents of children with disabilities can go through a developmental process of empowerment starting with identifying concerns about the child's development, then educating themselves and obtaining services, and finally in some cases engaging in efforts to assist other families and promote social change for other children with disabilities (Koren, DeChillo \& Friesen, 1992). Self-efficacy, or the belief in one’s abilities to achieve desired outcomes (Bandura, 1994), may be a particularly important aspect of the empowerment process. Parents’ feelings of self-control about being able to secure supports and resources for their children has been found to be positively correlated with their judgments about their parenting abilities (Dunst, 1999). Parental empowerment and its expression through advocacy may promote coping and resilience, especially in early childhood as parents adjust to 
the often overwhelming changes associated with becoming a parent, while also facing the challenges of caring for a child with special needs.

The exploratory research reported in this article is focused on the relationship between advocacy, self-efficacy, and empowerment. Whether parents choose to engage in advocacy may be influenced by their self-efficacy, or belief about their own abilities to serve as advocates for their children. Parents may feel empowered through their active efforts at self-education about their children's disabilities, attempts to secure appropriate services, and for some, their work to change public policies and social programs. This study begins to explore parents' feelings of self-efficacy and empowerment as related to advocacy.

Parents may become involved in advocacy after experiencing the distress of a diagnosis and feeling the need to mobilize for services (Resch et al., 2010). Others may become advocates after becoming dissatisfied with quality of their child's education (Wang et al., 2004). Advocacy is a dynamic process that changes based on the developmental needs of the individual with special needs. Young children need educational and social opportunities, like early intervention services. When children enter school, parents seek educational assessments and appropriate learning placements in the least restrictive environments. As children transition to secondary school, the focus of advocacy often shifts to community integration and preparation for adulthood, which may include supported or independent employment and living (Alper, Schloss \& Schloss, 1995).

Parents of young children with special needs may receive support and training to become advocates for their children if they participate in early intervention or preschool programs funded through the Individuals with Disabilities Act (IDEA), Parts B and C. "Enhancing the capacity of families to meet the special needs of the infants and toddlers,” (Bailey et al., 2006, p. 229) is a 
specific goal of the IDEA legislation, and preparing parents to be skillful and effective advocates for their children has been interpreted as a key part of this. Evidence that programs have been successful in meeting this goal includes parents demonstrating knowledge of their rights, service options for their children, and what to do if they feel needed services are not being provided (Bailey et al, 2006). A nationally representative survey of primary caregivers of children around three years of age who were completing early intervention found that the majority strongly agreed (65\%) or agreed (31\%) that they knew how to advocate for their children, and that they strongly agreed (50\%) or agreed (40\%) that they knew what to do if they felt that their children were not receiving appropriate services (Bailey et al., 2005).

While many parents of children with special needs are actively engaged as advocates for their children, they may encounter challenges and barriers than make this process difficult. These include the psychological and emotional experience of advocacy and cultural orientations. Parents' reactions to advocacy may depend on their perceptions of this role. Those who find it difficult can experience advocacy as a stressor (Nachshen \& Jamieson, 2000; Mlawer, 1993), whereas those who view advocacy as a coping mechanism may experience a reduction in stress when they achieve an advocacy success (Nachshen \& Jamieson, 2000). Bennett and colleagues (1997) note that "parents are often dismayed at having to be such strong self-advocates to professionals” (p. 126). Parents can find that the role of advocate puts them in an uncomfortable adversarial relationship with professionals (Bennett, Deluca \& Bruns, 1997; Trainor, 2010). Fear of being labeled as ‘trouble’ or being in the spotlight may hold some parents back from advocacy (Resch et al., 2010). This can be especially difficult for parents with cultural orientations that highly esteem professionals; some cultures perceive professionals as a source of unquestionable knowledge and parents may not expect to be treated as an equal and collaborator in making 
decisions on behalf of their child. Moreover, the level of assertiveness needed for advocacy can conflict with cultural norms (Kalyanpur, 2000).

Economic status and logistical issues can also be a source of barriers to parental advocacy. High-income parents may be able to meet their child's needs for extra support by paying for services, whereas lower income parents generally must request these types of services from schools and can be labeled as difficult (Coots, 1998). Yet those with middle income may be in the most difficult situation, with challenges paying out of pocket and fewer subsidies (Resch et al, 2010). Lower income families may have more difficulty recognizing needs related to their children's development, a necessary antecedent to advocacy, due to the presence of other unmet needs in the family (Dunst, Trivette \& Deal, 1988, cited in Mlawer, 1993). Finally, logistical issues can present challenges, particularly for low-income families. Schools may schedule meetings at short notice and at times difficult for parents to attend (Linan-Thompson \& Jean, 1997; Harry, Allen \& McLaughlin, 1995), particularly for lower income families with less ability to change work schedules (Lareau \& Shumar, 1996). Reading level of materials sent to parents may not be appropriate and comprehensible (Harry, 1992; Leung, 1996; LinanThompson \& Jean, 1997), particularly when non-English speaking parents are sent materials in English only (Weiss \& Coyne, 1997). Behavior of professionals may also serve as logistical deterrents to advocacy, including limited time for conferences; emphasis on documents rather than participation; and use of professional jargon (Harry, Allen \& McLaughlin, 1995).

Parent support groups and organizations, via the Internet and in person, are a key source of support for parents in their role as advocates. Parents may gain access to information on disabilities and methods for approaching special education that can result in more strategic advocacy (Trainor, 2010). They may form social relationships with other parents to provide 
mutual support and reduce feelings of social isolation (Black \& Baker, 2011). Parent groups can also provide specialized trainings and offer a chance to join with other parents for collective action (Madden, 1995).

Parental advocacy can and has resulted in important outcomes at the micro and macro levels. At the micro level, advocacy can result in improved services for the child and better quality of life for the family. While many parents may focus on advocacy for their child only (Kalyanpur \& Harry, 1999; Vincent, 2000), for some, the personal becomes political, as advocacy becomes activism (Zaretsky, 2004), and involves joining with other parents to transform systems and encourage more responsive services. At the macro level, parental advocacy can promote legislative changes, improved public awareness and community education, and more funding directed at disability services and research (Balcazar et al, 1996; Black \& Baker, 2011).

Given the importance of parental advocacy, particularly in the early years, a better understanding is needed about the contexts in which parents of young children advocate for their children and the advocacy processes in which parents engage. This study addresses the following research questions:

1) What are the settings in which parents advocate for their young children?

2) What are their levels of perceived effectiveness in different settings?

3) Are there basic processes related to advocacy across different settings, and if so, what are these processes?

The authors hypothesize that as parents improve their knowledge and skills, the perceived effectiveness of their advocacy efforts may contribute to a developmental empowerment process that may ultimately promote positive outcomes, including coping and resilience. This 
descriptive, exploratory research lays the foundation for exploring the issues of empowerment, coping, and resilience in greater detail through a follow-up interview portion of this study.

\section{Methods}

The study received IRB exemption from San Francisco State University and California State University, East Bay, in September 2012. A 20-minute anonymous online survey was released via Surveymonkey (www.surveymonkey.com) in October 2012. The online survey link was sent to email lists and Facebook groups for parents of children with special needs, of which the second author is a member, and individuals were encouraged to forward the link to other parents. A snowball sampling strategy was utilized because this is a difficult to locate population (Babbie, 2010). Based on the geographic distribution of study respondents, this snowball sampling strategy was effective in soliciting participants from 38 states and six countries.

\section{Measures}

Participants completed a general survey about parental advocacy. While the survey was completed by parents of children ages birth to $18(n=400)$, this article only reports on a subset of the survey data from parents of children ages birth to $6(n=76)$. The survey consisted of 18 questions, and was intended to be completed in 15 minutes or less. It was designed to be as brief as possible to maximize the number of responses. Shorter web-based surveys generally have higher response rates (Weimiao \& Yan, 2010). The survey was developed through formal and informal conversations with academic colleagues and parents of children with special needs. Many of the demographic questions were drawn from Surveymonkey’s extensive database of pre-tested questions. The reliability and validity of survey items was not determined.

Questions were primarily close-ended (i.e. demographics, rating scales, etc.). An example close-ended question is: In which settings have you advocated for your child (please 
check all that apply): schools, medical clinics, social services, churches, rallies or other community events, politician's offices, social media, other. This question was followed by another close-ended question: For each setting you selected above, please rate how effective you felt your advocacy has been in that setting, with 1 being totally ineffective and 5 being highly effective.

Given the study's theoretical framework, which emphasizes self-efficacy, parents’ perceptions about the effectiveness of their advocacy efforts was seen as most relevant. Thus, the survey instrument did not prompt parents with a definition of effectiveness or try to measure outcomes of their efforts in an objective sense. The exploratory nature of this study, as well as planned future research in this area, will allow for the development a concept of effectiveness related specifically to parental advocacy for children with special needs that is grounded in data. To begin to develop the concept of what parents perceive as effective advocacy, the survey included one open-ended question: Please describe, in as much detail as you can, your advocacy in one of the settings you described as effective or highly effective. How did you get involved? Who, if anyone, did you collaborate with? What happened? How did you feel about your efforts?

Fifty of the 76 parents answered this open-ended question. These responses were categorized by setting: schools, medical or rehabilitative/social services, community, and social media, political, and other settings. Throughout the qualitative findings section, direct quotes from parent responses are provided, with only minor corrections to clear typos or misspellings.

\section{Sample Characteristics}

Of the 400 participants who responded to the survey, 76 were parents of children under age six. The geographic distribution of the 76 parents of children under age six was slightly less diverse than in the larger study sample of 400 parents in that fewer were from outside of the 
U.S., and only 24 states were represented, with about 28\% being from California (where the second author resides). The remainder of the data presented here, including sample characteristics, focus exclusively on the sub-sample of 76 parents of children under age six.

The survey asked about race/ethnicity using an open-ended question: "Please describe your race/ethnicity.” The participants were overwhelmingly European American/White (79\%), with the remainder being Latino American (15\%), and less than 1\% being Asian American or multiple races/ethnicities. Five participants declined to state their racial/ethnic identity.

Nearly all of the parents (95\%) were female, and 91\% were married or in a domestic partnership. Close to one-third (32\%) reported an income of \$50,000-\$74,999. More than a quarter of the sample (27\%) had an income below \$50,000, and just over $40 \%$ had an income above $\$ 74,999$. The majority of participants in this sample were employed. Approximately onethird (32\%) of the participants reported working 40 or more hours per week, and 26\% reported working 1-39 hours per week. This sample is more affluent than the United States population of families in general who have children with disabilities, of whom approximately $30 \%$ are living in poverty (Murphey, Cooper \& Moore, 2012).

An overwhelming majority (90\%) of the parents reported having only one child with special needs. A little more than half (55\%) of the parents reported having a child between the ages of four and six years old. Approximately 40\% had a child between the ages of two and four. The remainder had a child under age two.

About half of the parents reported having a child with a chronic medical or physical health need. Close to one-third (30\%) of the parents described their child as medically fragile. A little less than half (45\%) had a child with a developmental or intellectual disability, not 
including autism. About one-third described having a child with autism. Participants could check more than one disability category, as many children have multiple disabilities.

\section{Data analysis}

Data analysis for the close-ended questions was conducted using descriptive statistics through Surveymonkey (http://www.surveymonkey.com/). Data from the open-ended question were analyzed using qualitative grounded theory methods, such as constant comparison (Dye, Schatz, Rosenberg \& Coleman, 2000). Efforts to ensure the reliability and validity of the analysis included assessing inter-rater reliability of the team's coding work and peer debriefing (Miles \& Huberman, 1994). Inter-rater reliability was assessed through numerous conversations between the co-authors, who independently developed broad categories for analysis of the data. A detailed coding scheme was not necessary for analysis of participants' relatively brief responses to the one open-ended question in the survey. The authors shared their broad categories and reached agreement on which categories to use in analysis. The authors met by phone and via email exchanges to address coding-related questions as they arose. Peer debriefing was done through conversations with academic colleagues and parents of children with special needs. These conversations centered on preliminary findings, areas of potential focus for additional analysis, and suggestions for future research.

\section{Quantitative Findings}

The focal point of the survey was on parents' advocacy activities. The close-ended questions were primarily intended to provide information about the settings in which parents engaged in advocacy activities, and their perceptions of its effectiveness (in response to research questions 1 and 2). Table 1 shows the settings in which parents advocated for their children and parents' perceptions of the effectiveness of their advocacy efforts. Nearly three-quarters of the 
parents advocated for their children in schools (71\%) and medical clinics (73\%). The next most frequent sites for advocacy were social services (58\%) and social media (51\%). Interestingly, more than one in five parents (22\%) have advocated for their children in politicians’ offices, indicating a possible macro focus for parents’ advocacy.

In response to the question about levels of perceived effectiveness of advocacy efforts in different settings, the most frequently selected settings for "highly effective” advocacy were schools (19\%), medical clinics (18\%), and social media (13\%). Table 1 shows the full responses to this question.

Insert Table 1 about here

\section{Qualitative findings}

To address research question 3, about whether there are basic processes related to advocacy across different settings and what those processes are, the survey asked parents to provide a short response to an open-ended question about their advocacy in a setting that the participant described as effective or highly effective. The participants were asked to describe, in as much detail as possible, how they became involved, with whom (if anyone) they collaborated, what happened as a result of the advocacy, and how they felt about the advocacy effort. This section describes main themes that emerged on the basic processes of parents' advocacy, with examples.

\section{Advocacy in Schools}

Fifteen parents described their advocacy in schools for their children. Parents discussed their efforts to gain access to occupational, speech, physical and other needed therapies, as well as to secure appropriate classroom placements. Parents employed three main techniques to advocate for their children: 1) educating, building rapport, and meeting with teachers and 
principals; 2) becoming familiar with special education law; and 3) collaborating with professionals outside the school and/or bringing advocates and supporters to Individualized Education Plan (IEP) meetings. Though parents described their efforts as successful, several expressed frustration about the time it takes to be an effective advocate and the stress they experience.

Parents commented on their efforts to build positive relationships with school staff and to educate them about their child's needs. One parent wrote, "I work hard to be appreciative of the work that school staff are already doing and help them to know how they have helped my son. I talk of positive changes and growth that I have seen in my son. I am polite but firm.” Another said, "In her school I went in and talked with them, taught them about Rett Syndrome and my daughter. I took ideas from other parents and websites associated with Rett Syndrome. They were very receptive and helped me to make sure she was and would get everything that would benefit her."

Some parents described their need to become experts in special education policies and procedures. For example, one parent wrote, “I advocate for my son in every single IEP meeting that we attend. First, I have become more educated about the IEP process, the rights provided my son with an IEP, etc. I have attended a Wright's Law training.” Parents often felt that this expertise was essential to getting their children access to needed services, as described by this parent:

My son was not receiving OT services from the school for a period of 6 weeks after his therapist went out on a medical leave unexpectedly. I wrote a letter and requested an emergency IEP. During the meeting I let them know they were not in compliance with the IEP and I requested an outside provider. The school district agreed to pay for the outside provider. If I would not have advocated, my son would not have received service for 5 months since that is what happened with other kids at his school. 
Several parents noted that they discussed their child's needs in formal and informal settings with therapists, doctors, psychologists, lawyers, special education advocates, and other parents to learn more about the services their children should be receiving, and to understand their child's rights with regard to accessing the services at school. A few parents also described bringing these professionals to IEP meetings to present expert opinions or provide moral support. This parent wrote about her successful efforts to secure an appropriate placement for her child:

In an IEP meeting, my 3 year old with Down Syndrome was going to be placed in a classroom with Severely Handicapped Students because of lack of space in a different special needs classroom. My son is not Severely Handicapped and was not a good fit in that classroom--there would have been no motivation for him to grow. It was the answer to the problem in our school district to just get him placed. We would not sign the IEP. Called an additional meeting, took an attorney and a Down Syndrome Advocate. Ended up with the best classroom placement ever. I have learned to not take NO for an answer!

Despite the effectiveness of parents’ advocacy efforts, some parents commented on feeling stressed by the need to advocate in order to obtain needed services. One parent wrote:

I feel exhausted and upset that sometimes I have to work very hard and "jump through hoops" and navigate extensive laws to get services for my daughter. I feel that so many parents don't have the time to do this, and it is not fair that some children get the services they are entitled to and others don't.

Another parent commented, "I have been continually amazed at the amount of effort that I have to put in to get an ideal program for my child...It also is distressing that I have to work as hard as I do to be sure she gets the education she deserves.”

\section{Advocacy in a Medical or Rehabilitative/Social Services Setting}

Seventeen parents described efforts to advocate for their children in a medical or rehabilitative services setting as an example of an effective or highly effective advocacy effort. 
Parents noted three main areas of success in terms of their advocacy efforts: 1) Educating themselves to request appropriate services and testing and deny unnecessary ones; 2) Educating medical professionals on the child's condition and research on treatment modalities; 3) Finding out what child is entitled to and pushing to get those services. A fourth area was also noted, with more mixed success, related to advocacy with insurance companies.

Parents noted the importance of educating themselves about their children’s diagnoses, in order to use that information for informed medical testing and procedures for their children. Parents described actively advocating for or against procedures, based on research and intuition about the benefits for their children. One parent described advocating for treatment for her child, who has had significant feeding issues throughout his life and recently had a gastric tube inserted in his abdomen. She noted that he never seemed hungry, and that she had learned of a gastric emptying study that could provide helpful information without requiring an invasive procedure. While professionals on his feeding team put off the procedure, she insisted, and the study found that he had delayed gastric emptying, a condition that could be treated. This success boosted her confidence in seeking appropriate treatment. Another parent had a similar advocacy success when she questioned a medical diagnosis given to her son of epilepsy after he experienced one seizure. Her child has a cerebral shunt, and she had poured over pediatric neurology journals and come to an appointment with a journal article in hand that suggested that a MRI test with sedation was warranted. The test revealed that her child is missing his right cerebellar hemisphere, with an appropriate diagnosis of Digenesis of the Corpus Collosum. This mother commented that if the doctor “Couldn't trust my instincts, then I couldn’t trust her to take care of my son.” Upon learning of the test results, the doctor did indeed apologize to the parent. 
An additional benefit of learning about the child's diagnosis and current research on treatment is educating medical professionals, so that they can ultimately provide better care to all children with a certain diagnosis. One parent described this role of educating medical professionals: "We have often had to bring our own research and information to doctors or other medical providers. They may be experts in one field, but no one can know everything, and it's important to make sure everyone has the best information.” One parent describes how she educated her pediatrician about her two children’s conditions of Autism, with a diagnosis of pervasive developmental disorder not otherwise specified (PDD-NOS). This pediatrician has added screenings for Autism to his practice, to enable early detection and treatment, after learning about the condition by treating the parent's two children. Another parent explained how she has advocated for changes in the medical system around the delivery of infants born with Trisomy 13 or 18 . She has reached out to pregnant women carrying children with this diagnosis and connected them with living children with Trisomy 13 or 18 , to learn about the joy these children bring. This parent has helped mothers inform their doctors about their wishes to deliver through C-section if their child cannot live through vaginal birth, and to request other aggressive interventions like tracheostomy, if those are the parents’ wishes.

Particularly in relation to rehabilitative services like physical and occupational therapy, parents described their efforts to find out what level or amount of services their children are entitled to, and to advocate for their children until those services are received. This took place for parents in school settings as well as outside specialized therapeutic programs. Two parents recounted their efforts to secure services through the state early intervention program. One of these parents described how her daughter was initially denied occupational therapy through the state early intervention program because she was just above the threshold of developmental 
delay that would qualify her. This parent then went to a psychologist for a diagnosis, of autism spectrum disorder, that would qualify her child for services. The early intervention program initially offered 10 hours of services a week, but the parent learned through a listserv on autism that her child could qualify for 40 hours a week of services with a more qualified professional due to her age. The parent was eventually able to get authorization for the amount of services requested, but encountered another barrier due to living rurally and a lack of qualified professionals in her area. Another parent also described her efforts to petition the state early intervention program for therapeutic services, in this case applied behavioral analysis for a child with autism. On the way to achieving victory, the parent sought advice from other parents on an autism listserv, consulted lawyers, and ultimately asked a lawyer to draft a letter requesting a certain amount of services and hinting at the possibility of an administrative hearing if the request was denied.

An area for advocacy where parents noted their ongoing persistence, but also frustrations and general lack of success, was with health insurance companies. One parent tried to get services associated with developmental disabilities covered by her insurer, without success. She was eventually able to get services covered by the child's school district instead. Another parent noted the long wait time to get insurance authorizations for treatment through a state-run health care program, and stated her intentions to continue to apply pressure until something changed. A third parent stated that a request for a particular type of rehabilitative service was denied by her insurer, but the denial was overturned by the state. This parent saw this as a victory not only for her family, but other parents as well.

\section{Community Settings}


Four parents described advocating for their child in other community settings. Three of these were churches, and one was a daycare program. Two of the parents who advocated in churches for their child were concerned about allergens in the snacks being provided. One parent was able to alert church childcare providers to her child's allergies by having her child wear a special name tag that reminded teachers of what her child could not eat. Another parent spoke with her church’s director and was successful in requesting that no snacks be served while children were in care. Another parent was concerned about her child's being able to participate in her church's children's program, and was successful in working with the ministers to receive necessary accommodations.

The parent who advocated for her child in a daycare setting experienced mixed success. She wanted her child to attend a daycare program with typically developing children, but the child needed a one-on-one aide. She requested assistance from her medical insurance company, but they initially denied the request. After hiring a lawyer, the request was approved, but she had difficulty finding a reliable aide. Eventually her child began kindergarten in a public school classroom for typically developing children, and he was able to have an aide in that setting.

\section{Social Media, Political, and Other Settings}

Two other primary forms of advocacy emerged from parents’ comments. Five parents described advocating for their child through educating the public, by sharing their child's story through methods like social media. Three parents described macro advocacy efforts to change services and policies, through political advocacy or starting an advocacy organization.

Parents described educating others about their child, with the specific aims of destigmatization and connecting with other families who have children with the same diagnosis. Social media is one method used for this end, with parents noting how they share pictures and 
stories of their children on social media platforms like Facebook and Caringbridge. One parent described the purpose of this as "[to] show how [her son] is just like you and should be treated equally.” Another parent described making a presentation to middle school children about Fragile $\mathrm{X}$ and her son. Two of these efforts mentioned trying to eliminate the "r word" as a particular goal of this public outreach. Other parents noted that they used social media to seek out other families with children who shared the same condition as their own, both to offer and receive support. A mother described how she sought connections with other mothers when she learned during pregnancy that her child would have a birth defect. Having received help “with open arms,” she now hopes “to help someone the same way someone helped me.”

A few parents commented on macro political and social advocacy as their primary achievement. Two parents formed relationships with their legislators to encourage the development and passage of legislation for individuals with disabilities. One parent persuaded her elected officials to sponsor bills that would influence funding and research for the National Institutes of Health. Another parent described her efforts to work with a state legislator on initiating a "Craniofacial Acceptance Month.” While the bill has stalled, she did note that these efforts resulted in legislators coming forward to share about their own children with conditions like cleft palate. One parent stated that she formed an advocacy organization for children with trisomy diagnoses.

\section{Discussion}

The purpose of this exploratory, descriptive study was to learn more about parental advocacy for children with special needs, including the settings in which parents advocate, perceived effectiveness of advocacy efforts, and advocacy processes. The study was informed by Bandura's (1994) concept of self-efficacy, in which individuals’ perceived ability to influence 
their environment and circumstances is experienced as empowering. Much of the literature on parents of young children with special needs has focused on the challenges of raising a child with a disability. Without sufficient exploration of parents' roles as active change agents in their children’s lives, there is a risk of viewing parents as passive, and losing an opportunity to collaborate with parents in supporting their children’s healthy development.

\section{Settings in which Parents Advocate for their Young Children and Perceived Effectiveness in these Settings}

This research found that parents are actively engaged in advocating on behalf of their young children, across a variety of settings including schools, medical services, and social media. Given this study’s theoretical framework of empowerment and self-efficacy, effectiveness was not defined for the parents. Rather, they determined their own self-definitions of effectiveness. Parents in this study identified the majority of their advocacy efforts as effective or highly effective in micro settings such as schools, medical clinics, and social services, while they less frequently engaged in macro advocacy involving rallies and community events and politician's offices, which was also deemed less effective. This split between the frequency of participation in micro and macro advocacy, and the differential perceptions of effectiveness, may be an avenue for future research. Parental advocacy at the macro level has been responsible for major structural changes in policies and programs that benefit families at the micro level (Parish \& Whisnant, 2006), suggesting the importance of supporting parents in policy advocacy.

\section{Processes Related to Advocacy Across Different Settings}

The primary processes found to be associated with parental advocacy are educating oneself about the child's condition as well as rights for accommodation and services; educating 
others, including medical and educational professionals as well as the general public, about types of disabilities and appropriate accommodations; and making persistent efforts so that the advocacy goal was achieved. In medical settings, parents described educating pediatricians and specialists and requesting as well as refusing testing and procedures. In educational settings, parents learned about special education law, educated teachers and principals, and brought in outside advocates when deemed necessary. In community settings and social media, parents educated clergy, friends, and neighbors about their children’s conditions, to encourage care and sensitivity.

Our findings suggest that parents experienced some of the key concepts related to empowerment, including self-efficacy, participation and collaboration, understanding the environment, and personal action (Dempsey \& Foreman, 1997; Dunst, Trivette \& LaPointe, 1992). Parents who participated in this study self-identified as their children's advocates and described the knowledge, skills, and strategies that they had developed to accomplish this role, which relates to the notion of self-efficacy. Their knowledge, skills, and strategies reflected their ability to understand and respond to their environments, partnering with others and engaging in personal action as required. Their perceptions of success with most advocacy efforts and ongoing persistence when encountering barriers fits with the notion of resilience, defined as accomplishing positive adaptation when facing adversity (Luthar, Cicchetti \& Becker, 2000). It is possible that there is a bi-directional relationship between self-efficacy, empowerment, and advocacy. Parents may be more likely to engage in advocacy efforts if they have a greater sense of self-efficacy. At the same time, when parents experience empowerment in the process of advocacy, they may discover inner strengths and new capacities that make them better advocates. 
This potentially bi-directional relationship will be explored through an analysis of in-depth interviews, currently being completed.

\section{Implications for Policy and Social Work Practice}

These findings demonstrate that advocacy for children with special needs begins in early childhood. Parents may need knowledge, skills, and support to become advocates for their children right after birth. For example, parents in this study describing effective advocacy efforts commented on the need to learn about their child's diagnosis, available interventions, and the laws pertaining to their child's treatment. They noted that they used collaborative and problemsolving skills to work with the professionals involved in their child's care. These are skills that some parents may need assistance in developing. Additionally, some parents commented on feeling "distressed" or "exhausted" by the need to advocate for their children so often. Parents may need psychosocial support and respite to maintain their well-being.

Parents who participate in early intervention through IDEA may receive training to become advocates for their children; however, eligibility for early intervention is limited to children with developmental delays, excluding other disabilities such as chronic medial and physical disabilities, and only a small percentage of children with developmental disabilities younger than 5 years old actually receive services (Rosenberg, Zhang, and Robinson, 2008). This suggests the need to expand policy initiatives like early intervention to other children with disabilities. It also raises the question of how parents not involved in early intervention develop and sustain their advocacy efforts, in early childhood and beyond. One potentially promising approach is Parent to Parent mentoring programs, a grassroots self-help model that offers parents of children with disabilities the opportunity to connect with and support other similar families. A study of Parent to Parent mentoring programs in 5 states found that these programs allowed 
families to share and gain practical information that made them feel better able to cope with challenges and feel more positive about their family and personal circumstances, though it did not identify significant improvement in perceived empowerment. Such programs may fill a policy niche in providing parenting support to parents of children with disabilities (Singer et al., 1999).

The findings also raise a question about the role of professionals working with families of children with special needs, and how they can promote empowerment of parents and ensure that children receive the services they need. Much of the burden for ensuring that children receive appropriate services falls upon parents. As one parent pointed out, this creates inherent inequality because "so many parents don't have the time to do this, and it is not fair that some children get the services they are entitled to and others don't.” Parents noted that they felt the need to educate professionals, suggesting that they are assuming responsibilities for continuing education that lie with the professionals themselves. In addition, the relentless need to advocate for one's child with professionals in education, health, and social services settings leads to parental exhaustion and frustration.

How much of the extra work done by parents should be assumed as best practice responsibilities by professionals? The empowerment role in social work suggests that social workers have a responsibility to promote client empowerment: “a process through which clients obtain resources - personal, organizational, and community — that enable them to gain greater control over their environment and attain their aspirations” (Hasenfeld, 1987, p. 479). The 1999 revisions to IDEA recognize the role of school social workers in particular to promote a homeschool-community approach to serving children with disabilities, which can include connecting families to parent organizations and educating parents about their legal rights to accommodations 
(Altshuler \& Koppels, 2003). Ways that social workers can support parents of children with special needs in terms of advocacy is another area where further exploration is needed.

\section{Strengths and Limitations of this Study}

Strengths of this study include its relatively large, national sample, and the context it provides for future research. The study also demonstrates that using a snowball sampling technique through online social networks is an effective means through which to recruit study participants. Participants’ willingness to complete the survey is an indication of the salience of this topic, suggesting that parents of children with special needs have great interest in discussing advocacy efforts on behalf of their children.

Limitations of this study include data collection exclusively through an online survey and in English. It is likely that this research design resulted in a sample that is more computer savvy, English literate, White/European American, and higher income than typical families of children with disabilities. Future research should consider these limitations by including alternate data collection methods, such as an in-person survey in community and educational settings. It is also important to capture the perspectives of parents for whom English is not the primary language. A study by Bailey and colleagues (1999) found that limited English proficiency was significantly associated with higher needs and lower social support for a sample of 200 Latino parents of children with special needs, factors that may suggest a lower capacity for advocacy.

Additional limitations of the study include that the survey was not designed specifically for parents of young children and the method of sample construction. The survey was intended for parents of children from birth to 18, and as such, did not include questions that might be only germane to parenting young children. In addition, the sample was constructed using snowball sampling, instead of probability sampling. This obviates the ability to identify prevalence of 
advocacy efforts in the overall population. The descriptive nature of the study is also a limitation, as is the limited amount of open-ended data collected.

\section{Conclusion and Recommendations for Future Research}

This article reports findings on parental advocacy for young children with special needs, exploring the settings in which parents advocate for their young children, their perceived effectiveness in different settings, and whether there are basic processes related to advocacy across different settings. The most frequent settings of parental advocacy were at the micro level and included schools, medical clinics, and social services. They rated the majority of these efforts as effective or very effective. Parents more rarely engaged in macro advocacy in settings such as politician's offices and rallies or community events, and perceived these efforts as less effective. Social media was another setting in which parents were active and reported overall perceived effectiveness. Across these settings, parents engaged in the same basic processes of educating themselves about their children's needs and rights; educating and sensitizing others, including professionals and community members; and remaining focused in their efforts to achieve the goals of their advocacy.

Future research is needed to capture the more complex relationships between advocacy, coping, empowerment, and resilience in parents of children with special needs. There is a second part of this study that begins to explore these topics, with the hope of developing a greater understanding of these relationships. After completing the survey, participants were invited to volunteer for an in-depth interview about their advocacy experiences. Almost 100 parents volunteered to be interviewed. In-depth interviews are currently being conducted. These interviews range in length from 20-90 minutes, and include detailed questions about effective advocacy efforts, advocacy efforts that did not seem effective, and factors the parents associate 
with effective advocacy, including personal characteristics, in-person and online social support networks, and personal resources. Findings for this second portion of the study will be released sometime in the next year.

It is also important to compare the experiences of the parents in this sub-sample, who have children under age six, to parents of older children and adults. In this sample, some parents described feeling exhausted by the need to advocate for their young children. The authors hypothesize that as parents increase in their knowledge and capacity to serve as advocates, they may feel less stressed and more empowered. A mixed methods longitudinal study would be ideal for testing this hypothesis. The findings reported in this article provide a context for future research, by providing information about settings in which parents advocate for their children, how they advocate, and whether they feel their advocacy efforts are effective. 


\section{References}

Alper, S., Schloss, P., \& Schloss, C. (1995). Families of children with disabilities in elementary and middle school: Advocacy models and strategies. Exceptional Children, 62(3), 261-270.

Altshuler, S. J., \& Kopels, S. (2003). Advocating in schools for children with disabilities: What's new with IDEA? Social Work, 48(3), 320-329.

Babbie, E.R. (2010) The basics of social research. Belmont, CA: Wadsworth, Cengage Learning.

Bailey, D.B., Bruder, M.B., Hebbeler, K., Carta, J., Defosset, M., Greenwood, C., Kahn, L., Mallik, S., Markowitz, J., Spiker, D., Walker, D., \& Barton, L. (2006). Recommended outcomes for families of young children with disabilities. Journal of Early Intervention, 28(4), 227-251.

Bailey, D.B., Hebbeler, K., Spiker, D., Scarborough, A., Mallik, S., \& Nelson, L. (2005). Thirtysix-month outcomes for families of children who have disabilities and participated in early intervention. Pediatrics, 116, 1346-1352.

Bailey, D.B., Skinner, D., Correa, V., Arcia, E., Reyes-Blanes, M.E., Rodriguez, P., VazquezMontilla, E., \& Skinner, M. (1999). Needs and supports reported by Latino families of young children with developmental disabilities. American Journal on Mental Retardation, 104(5), 437-451.

Bailey, D. B., Skinner, D., Hatton, D., \& Roberts, J. (2000). Family experiences and factors associated with the diagnosis of fragile X syndrome. Journal of Developmental \& Behavioral Pediatrics, 21(5), 315-321. 
Balcazar, F. E., Keys, C. B., Bertram, J. F., \& Rizzo, T. (1996). Advocate development in the field of developmental disabilities: A data-based conceptual model. Mental RetardationWashington, 34(6), 341-351.

Bandura, A. (1994). Self-efficacy. In V. S. Ramachaudran (Ed.), Encyclopedia of human behavior (Vol. 4, pp. 71-81). New York: Academic Press.

Bennett, T., Deluca, D., \& Bruns, D. (1997). Putting inclusion into practice: Perspectives of teachers and parents. Exceptional Children, 64(1), 115-131.

Berlin, L. J., Brooks-Gunn, J., McCarton, C., \& McCormick, M. C. (1998). The effectiveness of early intervention: Examining risk factors and pathways to enhanced development. Preventive Medicine, 27(2), 238-245.

Black, A.P., \& Baker, M. (2011). The impact of parent advocacy groups, the Internet, and social networking on rare diseases: The IDEA League and the IDEA League United Kingdom example. Epilepsia, 52(2), 102-104.

Carr, G. F. (2011). Empowerment: A framework to develop advocacy in African American grandmothers providing care for their grandchildren. ISRN nursing, 2011, 1-7.

Coots, J.J. (1998). Family resources and parent participation in schooling activities for their children with developmental delays. Journal of Special Education, 31, 498-520.

Dempsey, I., \& Foreman, P. (1997). Toward a clarification of empowerment as an outcome of disability service provision. International Journal of Disability, Development and Education, 44(4), 287-303.

Dunst, C. J. (1999). Placing parent education in conceptual and empirical context. Topics in Early Childhood Special Education, 19, 141-147. 
Dunst, C. J., Trivette, C. M., \& LaPointe, N. (1992). Toward clarification of the meaning and key elements of empowerment. Family Science Review, 5(1/2), 111-130.

Duquette, C., Stodel, E., Fullarton, S., \& Hagglund, K. (2011). Educational advocacy among adoptive parents of adolescents with fetal alcohol spectrum disorder. International Journal of Inclusive Education, 16(11), 1203-1221.

Dye, J. F., Schatz, I. M., Rosenberg, B. A., \& Coleman, S. T. (2000). Constant comparison method: A kaleidoscope of data. The Qualitative Report, 4(1/2), 1-9.

Glascoe, F. P. (1999). Using parents' concerns to detect and address developmental and behavioral problems. Journal for Specialists in Pediatric Nursing, 4(1), 24-35.

Gupta, A., \& Singhal, N. (2004). Positive perceptions in parents of children with disabilities. Asia Pacific Disability Rehabilitation Journal, 15(1), 22-35.

Harry, B. (1992). Restructuring the participation of African-American parents in special education. Exceptional Children, 59, 123-131.

Harry, B., Allen, N., \& McLaughlin, M. (1995). Communication versus compliance: AfricanAmerican parents’ involvement in special education. Exceptional Children, 61, 364-377.

Hasenfeld, Y. (1987). Power in social work practice. The Social Service Review, 61(3), 469-483.

Hess, R. S., Molina, A. M., \& Kozleski, E. B. (2006). Until somebody hears me: Parent voice and advocacy in special educational decision making. British Journal of Special Education, 33, 148-157.

Kalyanpur, M. (2000) Equity and advocacy expectations of culturally diverse families' participation in special education. International Journal of Disability, Development and Education, 47(2), 119 -136. 
Kalyanpur, M., \& Harry, B. (1999). Culture in special education: Building reciprocal familyprofessional relationships. Baltimore, MD: Paul H. Brookes Publishing.

Koren, P. E., DeChillo, N., \& Friesen, B. J. (1992). Measuring empowerment in families whose children have emotional disabilities: A brief questionnaire. Rehabilitation Psychology, 37(4), 305.

Lareau, A. \& Shumar, W. (1996). The problem of individualism in family-school policies. Sociology of Education, 69, 24-39.

Leung, B.P. (1996). Quality assessment practices in a diverse society. Teaching Exceptional Children, 28(3), 42-45.

Levine, K. A. (2009). Against all odds: Resilience in single mothers of children with disabilities. Social Work in Health Care, 48(4), 402-419.

Linan-Thompson, S. \& Jean, R. (1997). Completing the parent participation puzzle: Accepting diversity. Teaching Exceptional Children, 3, 46-50.

Lock, T. M., Shapiro, B. K., Ross, A., \& Capute, A. J. (1986). Age of presentation in developmental disability. Journal of Developmental \& Behavioral Pediatrics, 7(6), 340-345.

Luthar, S. S., Cicchetti, D., \& Becker, B. (2000). The construct of resilience: A critical evaluation and guidelines for future work. Child Development, 71(3), 543-562.

Madden, P. (1995). Why parents: How parents. British Journal of Learning Disabilities, 23(3), 90-93.

McCammon, S.L., Spencer, S.A., \& Friesen, B.J. (2001). Promoting family empowerment through multiple roles. Journal of Family Social Work, 5(3), 1-24.

Miles, M. B., \& Huberman, A. M. (1994). Qualitative data analysis: An expanded sourcebook. Thousand Oaks: Sage Publications. 
Mlawer, M.A. (1993) Who should fight?: Parents and the advocacy expectation. Journal of Disability Policy Studies, 4, 105-116.

Murphey, D., Cooper, M., \& Moore, K.A. (2012). Children with disabilities: State-level data from the American Community Survey. Child Trends Research Brief, Publication, \#2012-29. Washington, D.C.: Child Trends.

Nachshen, J., \& Jamieson, J., (2000) Advocacy, stress and quality of life in parents of children with developmental difficulties. Developmental Disabilities Bulletin, 28(1), 39-55.

Olsson, M. B., \& Hwang, C. P. (2001). Depression in mothers and fathers of children with intellectual disability. Journal of Intellectual Disability Research, 45(6), 535-543.

Parish, S.L. \& Whisnant, A.I. (2006). Policies and programs for children and youth with disabilities. In J.M. Jenson \& M.W. Fraser (Eds.), Social policy for children \& families: A risk and resilience perspective (pp. 167-194). Thousand Oaks: Sage Publications.

Rayner, M., \& Moore, P. S. (2007). Stress and ameliorating factors among families with a seriously ill or disabled child. E-Journal of Applied Psychology, 3(1), pp. 86-93.

Resch, J.A., Mireles, G., Benz, M.R., Grenwelge, C., Peterson, R., \& Zhang, D. (2010). Giving parents a voice: A qualitative study of the challenges experienced by parents of children with disabilities. Rehabilitation Psychology, 55, 139-150.

Rivera, J. A. (2009). Disability and the self-reliant family: Revisiting the literature on parents with disabilities. Marriage \& Family Review, 45(5), 431-447.

Rosenberg, S., Zhang, D., \& Robinson, C. (2008). Prevalence of developmental delays and participation in early intervention services for young children. Pediatrics, 121(6) e1503e1509. 
Shevell, M. I., Majnemer, A., Rosenbaum, P., \& Abrahamowicz, M. (2001). Profile of referrals for early childhood developmental delay to ambulatory subspecialty clinics. Journal of Child Neurology, 16(9), 645-650.

Sices, L. (2007). Developmental screening in primary care: The effectiveness of current practice and recommendations for improvement. Washington, D.C.: The Commonwealth Fund.

Singer, G. H., Marquis, J., Powers, L. K., Blanchard, L., DiVenere, N., Santelli, B., Ainbinder, J.G., \& Sharp, M. (1999). A multi-site evaluation of parent to parent programs for parents of children with disabilities. Journal of Early Intervention, 22(3), 217-229.

Tervo, R. C. (2005). Parent’s reports predict their child’s developmental problems. Clinical pediatrics, 44(7), 601-611.

Trainor, A. (2010). Diverse approaches to parent advocacy during special education home school interactions. Remedial and Special Education, 31, 34-47.

Turnbull, A.P., \& Leonard, J. (1981). Parent involvement in special education: Emerging advocacy roles. School Psychology Review, 10(11), 37-44.

Vincent, C. (2000). Including parents: Education, citizenship and parental agency. Buckingham: Open University Press.

Wang, M., Mannan, H., Poston, D., Turnbull, A. P., \& Summers, J. A. (2004). Parents' perceptions of advocacy activities and their impact on family quality of life. Research and Practice for Persons with Severe Disabilities, 29(2), 144-155.

Weimiao, F., \& Yan, Z. (2010). Factors affecting response rates of the web survey: A systematic review. Computers in Human Behavior, 26(2), 132-139.

Weiss, B.D., \& Coyne, C. (1997). Communicating with patients who cannot read. The New England Journal of Medicine, 337, 272-274. 
Zaretsky, L. (2004). Advocacy and administration: From conflict to collaboration. Journal of Educational Administration, 42(2), 270-286. 


\begin{tabular}{|c|c|c|c|c|c|c|c|}
\hline \multicolumn{8}{|l|}{ Table 1} \\
\hline \multicolumn{8}{|c|}{ Settings in which Parents Advocated and Self-Perceptions of the Effectiveness of Advocacy Efforts $(n=76)$} \\
\hline & $\begin{array}{l}\text { Percent that } \\
\text { advocated in } \\
\text { this setting }\end{array}$ & \multicolumn{6}{|c|}{ Perception of effectiveness of advocacy in this setting, by percent } \\
\hline Schools & 71.2 & 16.4 & 1.5 & 6.0 & 13.4 & 43.3 & 19.4 \\
\hline Medical clinics & 72.6 & 11.9 & 3.0 & 7.4 & 9.0 & 50.8 & 17.9 \\
\hline Social services & 57.5 & 23.2 & 1.8 & 5.3 & 16.1 & 44.6 & 9.0 \\
\hline Politician's offices & 21.9 & 61.7 & 4.3 & 0.0 & 17.0 & 12.8 & 4.3 \\
\hline Social media & 50.7 & 30.2 & 2.0 & 5.7 & 15.1 & 34.0 & 13.2 \\
\hline
\end{tabular}

